\title{
LA PRENSA DEL MOVIMIENTO NACIONALISTA REVOLUCIONARIO TACUARA EN LAS MUTACIONES DEL NACIONALISMO ARGENTINO
}

\author{
The press of the Tacuara Revolutionary Nacionalist Movement in the mutations \\ of argentine nationalism
}

\author{
Esteban Campos* \\ https://orcid.org/0000-0002-8213-7048
}

\section{Resumen}

Tacuara del manchón fue la prensa oficial del Movimiento Nacionalista Revolucionario Tacuara (MNRT) liderado por Joe Baxter y José Luis Nell, una fuente documental que hasta el momento no ha sido tratada de manera privilegiada por ninguna investigación. El análisis de los tres números que tuvo la publicación en 1963, permitirá revisar las concepciones del MNRT sobre la revolución, la vanguardia, el peronismo, el tercer mundo, la raza y la clase social. Estas categorías serán comparadas con otras publicaciones del universo tacuarista, como Tacuara. Vocero oficial de la juventud nacionalista, Ofensiva y Barricada. La idea que gobierna este trabajo es que Tacuara del manchón puso en palabras una pequeña pero significativa mutación del nacionalismo argentino: el pasaje de la ideología nacional-católica del Movimiento Nacionalista Tacuara, caracterizada por una teología política en clave racialista, a un nacionalismo más secularizado, interesado en la emancipación económica y social del Tercer Mundo.

$$
<\text { Nacionalismo }><\text { Tercer mundo }><\text { Raza }><\text { Clase social }><\text { Teología política }>
$$

\begin{abstract}
Tacuara del manchón was the press publication of the Tacuara Revolutionary Nationalist Movement led by Joe Baxter and José Luis Nell, a documentary source that until now has not been studied in a privileged way in any research. The analysis of the three issues published in 1963 will allow to examine MNRT's understandings of revolution, vanguard, Peronism, third world, race and social class. These categories will be compared to other publications within Tacuara's domain, such as Tacuara. Vocero oficial de la juventud nacionalista, Ofensiva and Barricada. The idea that guides this paper is that Tacuara del manchón put into words a small but significant mutation of Argentine nationalism: the passage from the national-Catholic ideology of the Tacuara Nationalist Movement, characterized by a political theology with a racial orientation, to a more secularized nationalism, interested in the economic and social emancipation of the Third World.
\end{abstract}

$<$ Nationalism $><$ Third world $><$ Race $><$ Social class $><$ Political theology $>$

* Instituto de Historia Argentina y Americana "Dr. Emilio Ravignani”, Buenos Aires, Argentina. Investigador Asistente del Consejo Nacional de Investigaciones Científicas y Técnicas (CONICET), Argentina. estebancampos1977@gmail.com 
Campos. La prensa del Movimiento Nacionalista Revolucionario Tacuara en las mutaciones del nacionalismo...

\section{Introducción}

Tacuara. Órgano del Movimiento Nacionalista Revolucionario Tacuara, también conocida como Tacuara del manchón, fue la prensa oficial del sector del MNRT liderado por Joe Baxter y José Luis Nell, con una existencia de tres números entre octubre y noviembre de 1963. Por ser una fuente documental mayormente olvidada o de difícil acceso para quienes se dedicaron a estudiar el Movimiento Nacionalista Tacuara (MNT) y sus agrupaciones derivadas, hasta el momento no ha sido abordada por ninguna investigación, salvo de manera lateral por Federico Finchelstein (2016, pp. 159-162). En el presente artículo se analizan las concepciones de Tacuara del manchón en torno a la revolución, la vanguardia, el peronismo, el tercer mundo, la raza y la nación, categorías que se revisaran de manera comparada con otras publicaciones del universo tacuarista como Tacuara. Vocero de la juventud nacionalista, Ofensiva y Barricada. La idea rectora que se pondrá a prueba en este trabajo es que Tacuara del manchón puso en palabras una pequeña pero significativa mutación del nacionalismo argentino: el pasaje de la ideología nacional-católica del Movimiento Nacionalista Tacuara, caracterizada por una teología política en clave racialista, a un nacionalismo más secularizado, interesado en la emancipación económica y social del Tercer Mundo. En este tránsito, el MNRT conservó varios elementos de la formación cultural anterior ya que, como afirma el lingüista Teun Van Dijk (2005, pp. 10-11), las ideologías son adquiridas gradualmente, independientemente de las variaciones personales y contextuales que puedan experimentar de manera brusca. Por esta razón, Tacuara y buena parte de sus agrupaciones derivadas no escaparon a las tendencias de la derecha global en los años ' 50 y ' 60 , que desplazaron su racismo racialista -inspirado en las teorías cientificistas de superioridad biológica entre razas- para defender en público un racismo culturalista de nuevo tipo (Traverso, 2014, p. 148 y Wieviorka, 1994, p. 39).

Dentro de las emergencias, los desplazamientos y las fusiones de movimientos radicales en la historia argentina reciente de los años ' 60 y ' 70 , el MNRT ha sido objeto, por lo general siempre en segundo plano, de una considerable cantidad de trabajos provenientes de la historiografía académica, el periodismo de investigación y las memorias militantes. En buena medida, esto se debe al cordón umbilical que unió a este grupo con el MNT, una organización política de la derecha nacionalista y católica de notable exposición pública entre 1958 y 1964. Los orígenes de Tacuara se remontan a un grupo de militantes de la Unión Nacionalista de Estudiantes Secundarios (UNES), que participaron activamente del golpe militar contra el gobierno constitucional de Juan Domingo Perón (Goebel, 2007, p. 362 y Padrón, 2017, p. 105). La ideología del MNT se remontaba al universo cultural de la derecha argentina y europea de entreguerras: el falangismo de José Antonio Primo de Rivera, el nacional-sindicalismo de Ramiro Ledesma Ramos, la historiografía revisionista y el antisemitismo católico del padre Julio Meinvielle, tronco al que se agregó la doctrina comunitarista de Jaime María de Mahieu. En sus propias categorías culturales, los tacuaristas no eran ni de izquierda ni de derecha, ya que se veían a sí mismos como una síntesis superadora de ambas corrientes. 
En una entrevista para el diario Crónica, su principal dirigente Alberto Ezcurra Uriburu distinguía la ideología de la organización:

\begin{abstract}
Nosotros partimos de bases católicas espiritualmente, políticamente nacionalista, sindicalista y comunitario en el orden económico (...) Se entiende por izquierda (...) un reordenamiento social y económico revolucionario. Por derecha se entiende la defensa de la religión, de la tradición y de la patria, y nosotros no queremos ni una cosa ni la otra, sino una síntesis de ambas, para romper con los moldes de izquierda y de derecha (...) Queremos una revolución social; pero con el signo de Dios y la bandera de la Patria. ${ }^{1}$
\end{abstract}

El crecimiento de Tacuara, la incorporación de nuevos militantes con un perfil más plebeyo y su acercamiento al peronismo generaron fuertes disidencias internas, que terminaron por fragmentar la organización. En octubre de 1960, un grupo cercano al padre Meinvielle rompió con el MNT para fundar la Guardia Restauradora Nacionalista (GRN), acusando a la agrupación de Ezcurra Uriburu de haber sido copada por "el fidelismo, el trotskismo y el ateísmo" (Bardini, 2002, p. 44). Otro núcleo de militantes conducidos por Dardo Cabo se separó de Tacuara en mayo de 1961 para crear el Movimiento Nueva Argentina (MNA), que se proclamó abiertamente peronista y forjó una estrecha relación con la Unión Obrera Metalúrgica. Finalmente, en diciembre de 1962 tuvo lugar la fractura del MNRT, a partir de un sector dirigido por Joe Baxter, José Luis Nell y Alfredo Ossorio, e integrado por otros militantes como Jorge Caffatti, Carlos Arbelos, Tomislav Rivaric, Horacio Rossi y Ricardo Viera, que se acercó a los sectores juveniles y sindicales del peronismo duro. ${ }^{2}$ Ésta Tacuara, que se definía peronista y revolucionaria, proclamaba la revolución nacional y social, se identificaba con los movimientos antiimperialistas del Tercer Mundo, compartía la lectura revisionista del pasado nacional, y concebía la lucha armada como el principal método para la toma del poder. Su estructura provenía de las brigadas sindicales del MNT y los comandos barriales de la Capital Federal, sin sostener, de acuerdo a los documentos y la bibliografía disponible, una presencia significativa a escala nacional ${ }^{3}$

A poco de andar, Ossorio y sus seguidores cuestionaron lo que veían como un giro a la izquierda del sector Baxter-Nell, y se congregaron en torno al periódico

\footnotetext{
1 "Los tacuaristas no somos asesinos, afirma su jefe". Crónica, 04/05/64.

2 El peronismo "duro" fue la autodenominación de la corriente sindical que se opuso a negociar con el presidente Arturo Frondizi en oposición a la conducción de la CGT, cuestionada por estos sectores como "blanda" y proclive a favorecer el proyecto integracionista del oficialismo. Algunos referentes de los "duros" fueron Sebastián Borro, Andrés Framini, Raimundo Villaflor y Gustavo Rearte (Bozza, 2001, pp. 135-169 y Raimundo, 2001, pp.203-226).

3 La investigación más completa hasta la fecha sobre Tacuara y sus agrupaciones derivadas, realizada por Juan Manuel Padrón (2017, pp. 151-200) no registra ninguna presencia de la Tacuara revolucionaria en el interior o el litoral, si bien en Barricada se comenta la realización de un acto de las "brigadas femeninas del MNRT" en la ciudad de Goya, Corrientes, en conmemoración de la muerte de José de San Martín, véase: Barricada, n.8, diciembre, 1964, s/p.
} 
Campos. La prensa del Movimiento Nacionalista Revolucionario Tacuara en las mutaciones del nacionalismo...

Barricada del nacionalismo revolucionario (más conocido como Barricada), con un discurso cercano a las ideas comunitaristas de De Mahieu. En agosto de 1963, un comando del MNRT vinculado al sector Baxter-Nell asaltó el Policlínico Bancario en el barrio porteño de Caballito, operativo que tuvo como saldo dos muertos, tres heridos, $\mathrm{y}$ un botín equivalente a 100.000 dólares. Parte de ese dinero le permitió a Joe Baxter iniciar un largo viaje que lo llevó a reunirse con Perón en Madrid, luego a Argelia y a Egipto, para ponerse en contacto con dirigentes políticos tercermundistas. Los miembros del MNRT que se quedaron en el país intentaron acercarse a los sectores capitaneados por Gustavo Rearte que confluyeron en el Movimiento Revolucionario Peronista, e incluso firmaron volantes con esa denominación. La organización fue herida de muerte en marzo de 1964, cuando una investigación policial develó la autoría del robo al Policlínico y se produjo una ola de arrestos. En la cárcel, un grupo de ex militantes del MNRT incorporó lecturas marxistas a su formación, sin abandonar el peronismo como identidad política. Algunos de ellos, como Jorge Caffatti, Carlos Arbelos y Alfredo Roca, continuaron su militancia en las Fuerzas Armadas Peronistas. Otros, como Joe Baxter y José Luis Nell, se vincularon al Ejército Revolucionario del Pueblo y a Montoneros, respectivamente.

Como he sugerido en un trabajo anterior (Campos, 2016, pp. 117-134), en las producciones historiográficas, periodísticas y testimoniales que se ocuparon de Tacuara pueden advertirse dos tendencias: la primera ve al MNT como un producto de la cultura política europea de entreguerras, que hunde sus raíces en la derecha nacionalista con simpatías fascistas de la Argentina. De allí la naturaleza vicaria del MNRT en algunos trabajos que abordan el universo tacuarista en conjunto, y su señalamiento de las dificultades que tuvo la Tacuara revolucionaria para ir más allá de los moldes culturales de la década de 1930 (Finchelstein, 2016; Galván 2008; Lvovich, 2009; Rock, 1993 y Senkman, 2001). Si bien es preciso reconocer que todos estos trabajos suelen tener en cuenta el impacto del peronismo y los acontecimientos de coyuntura nacional e internacional en las transformaciones del nacionalismo, la continuidad es uno de sus argumentos centrales. La segunda tendencia se concentra en el pasaje del MNT al MNRT y prioriza las rupturas, enfatizando el vínculo entre los años '50, '60 y '70 (Lvovich, 2012 , p. 14) $)^{4}$. En varios de estos trabajos se caracteriza a la Tacuara revolucionaria como la primera guerrilla urbana de la Argentina: el pasaje de dirigentes de esta agrupación por las principales organizaciones armadas, parece una condición suficiente para declarar el asalto al Policlínico Bancario de 1963 como el inicio del ciclo de violencia política que condujo al terrorismo de Estado. Derechas e izquierdas aparecen así reconciliadas por la violencia en una misma cultura política (Dandan y Heguy, 2006; García, 1963; Gasparini, 2006 y Gutman, 2003). En última instancia, los argumentos "continuistas" o "rupturistas" sobre Tacuara y sus diversos fraccionamientos le niegan una temporalidad específica a la coyuntura en la que surgen estas organizaciones, marcada por la guerra fría, el auge de las revoluciones anticoloniales y la proscripción del peronismo.

\footnotetext{
${ }^{4}$ Véase la introducción de Daniel Lvovich y los trabajos de Valeria Galván, Juan Manuel Padrón y Mario Gluck (2012).
} 
A pesar de su corta vida, minimalismo organizativo y escasa gravitación en la política argentina, el MNRT ha sido sobrerrepresentado por sus analistas como un nudo gordiano de las mutaciones políticas de los años ' 60 , un antecedente pionero de la nueva izquierda nacionalista, socialista, populista y guerrillera. El fuerte impacto en los medios de comunicación de la época del grupo liderado por Baxter y Nell, en parte logrado por la espectacularidad del asalto al Policlínico, en parte recibido como herencia del generoso espacio que la prensa periódica y el cine le habían dedicado a la Tacuara nacionalista, contribuyó a agigantar su imagen retrospectiva. Esta distorsión contrasta con las dificultades para reunir el corpus documental de Tacuara y sus diversos fraccionamientos. Si para las organizaciones de izquierda existen fondos accesibles e incluso archivos digitales, no ocurre lo mismo con el MNT, el MNRT, el MNA y la GRN, que nos han legado una documentación fragmentaria, dispersa e incompleta. En efecto, la mayoría de los trabajos que abordaron al MNRT lo hicieron sin ocuparse de Tacuara del manchón, a lo sumo conformándose con relevar Barricada, una publicación que desarrolló contenidos y miradas sensiblemente diferentes a la prensa del sector capitaneado por Baxter y Nell ${ }^{5}$.

El primer número de Tacuara del manchón salió a la luz la primera quincena de octubre de 1963, en coincidencia con la asunción presidencial del radical Arturo Illia. El periódico tenía cuatro modestas páginas que medían 32 x 48 centímetros, y era dirigido por Julio Ríos, quien se mantuvo como responsable los tres números que duró la publicación. ${ }^{6}$ En este primer ejemplar se puede leer debajo del título, en letras muy pequeñas, Tacuara. Órgano del Movimiento Revolucionario Tacuara, como un reflejo invertido del Movimiento Nacionalista Tacuara, donde la " $\mathrm{R}$ " de revolucionario parece sustituir a la $\mathrm{N}$ del MNT, que ya no era visto como una alternativa radical por el grupo de Baxter y Nell. Recién en el segundo número se conoció la nueva denominación de la organización como Movimiento Nacionalista Revolucionario Tacuara, con el que serían reconocidos por el conjunto del activismo político, la prensa y los servicios de inteligencia. Debajo de la información sobre el origen de la publicación aparece como lema editorial un aforismo de Eva Perón, "[1] a patria dejará de ser colonia, o la bandera flameará sobre sus ruinas", signo distintivo de la mutación identitaria del MNRT. En realidad, Tacuara del manchón era un nombre despectivo, que provenía de las amargas quejas de la dirigencia del MNT, cuando comprobó la existencia de un periódico con el mismo nombre de su publicación oficial:

\footnotetext{
5 Algunos ejemplares de Barricada, Tacuara. Vocero de la Juventud Nacionalista y Ofensiva están digitalizados en sitios web como www.eltopoblindado.com, o pueden consultarse en el Centro de Documentación e Investigación de las Izquierdas (CEDINCI), aunque en una cantidad reducida. El Instituto Bibliográfico Antonio Zinny posee unos pocos números de estas dos últimas publicaciones, pero me fue imposible consultarlas ya que los responsables de la institución adujeron problemas presupuestarios para sostener la consulta del archivo. Gracias a la generosidad del historiador mexicano Luis Alberto Herrán Ávila, pude acceder a los tres números de Tacuara del manchón y a diversos medios de prensa de la derecha nacionalista.

6 Julio Ríos sería un nombre de fantasía, véase: Entrevista a Alfredo Ossorio, realizada por el autor (17/07/2017). Junto a él se desempeñaban como redactores Joe Baxter, Ricardo Viera, Jorge Sorel y Horacio Rossi (Carman, 2015).
} 
Campos. La prensa del Movimiento Nacionalista Revolucionario Tacuara en las mutaciones del nacionalismo...

Anda por ahí un periódico apócrifo que lleva el nombre de "Tacuara", vocero de un pretendido "Movimiento Nacionalista Revolucionario Tacuara", que ha reemplazado nuestra lanza montonera por un manchón surrealista plagiado de "La Vanguardia Roja". No tocaríamos este tema si no fuera porque en él aparecen las firmas de algunos que hasta ayer militaron junto a nosotros, y hoy han quedado por el camino. Y esto puede prestarse a confusión. Para quedar bien en claro, basta observar el estilo de estos disfrazados, cuyas características son la demagogia declamatoria y el intelectualismo marxistoide. ${ }^{7}$

Para la Tacuara nacionalista dirigida por Ezcurra Uriburu, la forma hacía al contenido; alcanzaba con ver las coincidencias en el lenguaje y la estética que compartían la publicación del MNRT y el periódico La Vanguardia Roja, del Partido Socialista Argentino de Vanguardia, para definir al nuevo agrupamiento como una banda de marxistas disfrazados de nacionalistas (Tortti, 2007, pp. 225). En lo que sigue, veremos una síntesis de las definiciones políticas e ideológicas que la Tacuara revolucionaria pudo desarrollar a lo largo de los tres números que duró Tacuara del manchón.

\section{Revolución, vanguardia y peronismo}

Juventudes generadoras son esas minorías quijotescas que realizan lo que las multitudes sanchezcas no se atreven a hacer. Nuestra generación avanza sobre los escombros del régimen caduco para plasmar la arquitectura revolucionaria de la Nueva Argentina ${ }^{8}$.

Junto al "manchón surrealista", que había sido objeto de burla por parte de Ezcurra Uriburu, lo más llamativo en la portada del primer número de Tacuara del manchón es la consigna que aparece en el lateral izquierdo de la parte inferior: "Del proletariado y la clase media con conciencia Nacional y Social surgirán los soldados del ejército de Liberación Nacional que gestarán la Revolución Nacional y Socialista. Una Revolución que sea de los argentinos y para los argentinos". El contenido de esta consigna se explica mejor en la editorial firmada por Joe Baxter:

Nosotros creemos que el nacionalismo tiene una tarea que

\footnotetext{
7 "Disfrazados", Tacuara. Vocero de la juventud nacionalista s/n., noviembre, 1963, p. 2. Ésta era la prensa oficial de la Tacuara nacional-católica, que publicó seis números entre 1958 y 1964. Ofensiva fue un medio de circulación interno del Departamento de Formación del MNT, que tenía como fin homogeneizar ideológicamente a las distintas agrupaciones tacuaristas que respondían a Ezcurra Uriburu en Buenos Aires (Padrón, 2017, pp. 139-141). Aunque adoptar el nombre con el que los tacuaristas opositores señalaron negativamente a la prensa del MNRT es problemático, prefiero la denominación Tacuara del manchón para diferenciar claramente a esta publicación de Tacuara. Vocero de la juventud nacionalista, y también por razones de comodidad para los/las lectores/as del artículo, dada la extensión del nombre original.

8 "Generación y juventud", Tacuara. Vocero Oficial de la UNES, n. 4, 1946.
} 
cumplir, que es precisamente la de crear la Nación, dándole forma y contenido; creemos que se debe trabajar sobre bases reales y lógicas (...) Argentina, para constituirse en nación, debe dejar de ser colonia, ello implica no sólo lograr la independencia política (que por supuesto no tenemos), sino que además debe liberarse económicamente, ello exige una total transformación económico-social, por cuanto las actuales estructuras que tanto defienden ciertos «nacionalistas» son el instrumento de sujeción que utiliza el imperialismo, de ahí que nosotros demos fundamental importancia al estudio de los problemas económicos. ${ }^{9}$

La Argentina se podía caracterizar como un país subdesarrollado y colonial, diagnóstico que permitía determinar la naturaleza de las tareas revolucionarias. Había que abolir las estructuras que garantizaban la opresión, por eso Baxter le otorgaba "fundamental importancia" al estudio de la economía, una novedad en la formación de los cuadros tacuaristas, donde el tema ocupaba un lugar marginal. En efecto, hacia 1959 el servicio de librería "Darwin Passaponti" del MNT ofrecía más de veinte títulos a sus militantes, entre los que se encontraban obras como "Peregrinación de luz de día", de Juan Bautista Alberdi, "Vida y muerte de López Jordan", de Fermín Chávez, "Proceso al liberalismo argentino", de Atilio García Mellid, "Antes que la Constitución fue la Nación", de Enrique P. Oses, "El Estado totalitario en el pensamiento de José Antonio", de José Luis de Arrese, "El orgullo judío", de H. Vries Heekelingen y "Mi lucha" de Adolfo Hitler, entre otros textos. ${ }^{10}$ En el horizonte programático del MNRT, el modelo a seguir era el régimen revolucionario de Ahmed Ben Bella en Argelia, como explicaba Joe Baxter en otro artículo:

Si bien cada nación deberá recorrer su propio camino hacia la liberación, hay ciertos aspectos fundamentales en las que todas deben coincidir, la construcción del socialismo es la más importante, Ben Bella lo sabe muy bien y desde la toma del poder fue dando todos los pasos para [construir] en Argelia un socialismo nacional, el cual no tiene obligatoriamente que ser marxista-leninista, tratándose de un país donde la mayoría de la población es fervientemente religiosa, y la religión es uno de los factores formativos de lo nacional. La realidad impone a los países del tercer mundo, como único camino de liberación, el socialismo. ${ }^{11}$

\footnotetext{
9 Baxter, J. J., "Nacionalismo", Tacuara. Órgano del Movimiento Revolucionario Tacuara, n.1, octubre, primera quincena, 1963, p. 1.

10 "Servicio de librería Darwin Passaponti", Tacuara. Vocero de la Juventud Nacionalista, n. 7, 1959, p. 2.

${ }^{11}$ Baxter, J. J., "Ben Bella y el Tercer Mundo", Tacuara. Órgano del Movimiento Nacionalista Revolucionario Tacuara, n. 2, octubre, segunda quincena, 1963, p. 4.
} 
Campos. La prensa del Movimiento Nacionalista Revolucionario Tacuara en las mutaciones del nacionalismo...

Para el dirigente del MNRT, la Revolución argelina era "la concreción de nuestros más caros ideales". Un socialismo basado en la reforma agraria, la expropiación de las empresas extranjeras y la nacionalización de sectores estratégicos de la economía, pero con la peculiaridad de ser nacionalista, islamista y antimarxista (Goldar, 1972, pp. 142-150). En este pasaje, el documento ofrece indicios por lo que dice, pero también por lo que no dice: ¿no era la reivindicación de la Revolución Argelina, con su socialismo alternativo al paradigma marxista-leninista, un disparo por elevación al castrismo predominante en los modelos revolucionarios de la década del '60? Si cada nación tenía que recorrer su propio camino revolucionario, el MNRT creía que el peronismo debía ser el lugar de la fusión entre vanguardia nacionalista y clase obrera:

El proletariado es la única clase del país que tiene Conciencia Nacional y su permanente militancia antioligárquica y antiimperialista lo convierten en motor de la Revolución Nacional (...) su condición de clase oprimida le ha dado una mayor conciencia del cambio radical que es necesario realizar en las estructuras económico-sociales. ${ }^{12}$

Esta lectura marxista, donde los actores sociales se organizan de manera agonal según el lugar que tienen asignado en el proceso de producción, significó una ruptura con el discurso tacuarista tradicional, que rara vez utilizaba términos como proletariado y lucha de clases. ${ }^{13}$ En palabras de Julio Ríos, el ascenso de Perón en 1943 había permitido que el "proletariado nacional de origen provinciano" se incorpore a la vida gremial y política del país. Por esta razón, el peronismo era caracterizado como un movimiento nacional revolucionario, aunque con reservas:

"Su acción se ve frenada por el aburguesamiento de un sector importante- por los resortes que tiene en su poder- de dirigentes. La primera contradicción surge al observar la antinomia entre su capa "oficial" de representantes: burocratizada y reformista y los cuadros dirigentes de su juventud: rebelde y combatiente. El entronque de la minoría conductora con Conciencia Revolucionaria, que haga de puente entre el pueblo y su Líder, no puede esperar más." ${ }^{14}$

\footnotetext{
${ }^{12}$ Ríos, J., "Tacuara y la liberación nacional", Tacuara. Órgano del Movimiento Revolucionario Tacuara, n. 1, octubre, primera quincena, 1963, p. 4.

${ }^{13}$ En la muestra relevada de la prensa del MNT aparece una sola mención del significante "proletariado", v. "La democracia no sirve", Tacuara. Vocero de la Juventud Nacionalista, año XVIII, s/n, diciembre, 1963, p. 4. La lucha de clases es mencionada en pocas ocasiones, y con interpretaciones opuestas: si para Antonio Mille era una falsedad inventada por los comunistas europeos, para Oscar Denovi se trataba de "un hecho que desgarra profundamente a la sociedad moderna", v. Mille, A., "Occidente, es occidente", Tacuara. Vocero de la juventud nacionalista, n. 10 septiembre, 1961, p. 2 y Denovi, O., "Más allá del nacionalismo (I). El hecho de la lucha de clases", Ofensiva, n. 9, agosto, 1962, p. 5.

${ }^{14}$ Ríos, J., ob. cit., p. 4.
} 
Tal valoración crítica coincidía en varios aspectos con los argumentos de peronistas de izquierda como John William Cooke, Mario Valotta y Gustavo Rearte, que cuestionaban la burocratización de la dirigencia peronista y apostaban a construir una vanguardia revolucionaria dentro del movimiento. ${ }^{15}$ En la reivindicación emenerretista de las minorías conductoras, también se pueden advertir sedimentos del nacionalismo elitista predominante hasta mediados de la década de 1930; aquel nacionalismo de masas pasivas y líderes proteicos que había heredado la florida prosa de Ezcurra Uriburu, cuando definía al peronismo como "un inmenso flan que influye en la vida nacional por el solo peso muerto de su expresión numérica". ${ }^{16}$ Para Ríos, la diferencia entre los nacionalismos del MNT y el MNRT era que el primero tenía que "dejar de lado sus prejuicios de élite", mientras que el segundo, debía converger con los cuadros juveniles del peronismo duro. Si el nacionalismo no se apoyaba en el pueblo, sólo le restaba convertirse en fuerza de choque de la burguesía: "La disyuntiva es clara, o somos la Conciencia y la Vanguardia del Gran Movimiento Popular de Liberación Nacional o pasamos a ser la anestesia de la Revolución Nacional" ${ }^{17}$.

En otra nota llamada "Tacuara y el Movimiento Nacional", se repiten los conceptos vertidos sobre el peronismo, con el añadido de incluir a los trabajadores y "la eclosión popular ocurrida en 1945", en una larga saga de combates entre la patria y la antipatria, el pueblo y la oligarquía, que se remontaba a la época de las guerras civiles argentinas. ${ }^{18}$ Una definición arraigada en el revisionismo histórico, donde Perón era el jefe del movimiento nacional, y el nacionalismo su doctrina revolucionaria, si bien el peronismo todavía no era apto como herramienta para llevar adelante las tareas de la liberación nacional y social:

Evidentemente falta la minoría dirigente capaz de organizar el Movimiento para su función revolucionaria y racionalizar la intuitiva Conciencia Revolucionaria que tiene el pueblo peronista. No es que falten elementos capaces dentro de él, sino que estos ven frenada su acción por los elementos reformistas

\footnotetext{
${ }^{15}$ Baschetti (1997, pp.186-194, 198-203, 256-257, 327-329, 347-349) recopiló varios documentos donde aparece la cuestión de la vanguardia en el peronismo: "Reportaje a John William Cooke desde La Habana”, septiembre, 1961; Cooke, J. W. "Carta a Juan José Hernández Arregui”, 28/09/61; “Carta a dos compañeros de FOETRA, 1964; Valotta, M., "Nuevo punto de partida"agosto de 1963), Rearte, G., "Es la hora de las definiciones", noviembre 1964, Cooke, J. W., "Peronismo revolucionario", Cristianismo y Revolución n. 2-3, octubre-noviembre, 1966; Programa del Movimiento Revolucionario Peronista, Cristianismo y Revolución, n. 6-7, abril, 1968, pp. 14-15.

${ }^{16}$ Ezcurra Uriburu, A., "La crisis del peronismo", Ofensiva n. 11 (noviembre de 1962), pp. 3-4. El jefe del MNT criticaba al movimiento de Perón por su "carencia de cuadros revolucionarios, producto de la vaguedad doctrinaria y del lastre burgués que frustró al peronismo en el poder". En otra nota se sostenía que "(...) la Revolución sólo puede ser llevada a cabo por una minoría orgánica y adoctrinada, seleccionada por el proceso natural de decantación que se da en la lucha", v. "Aristocracia revolucionaria" (s/f), Tacuara. Vocero de la juventud nacionalista, año XVIII, s/n, diciembre 1963, p. 3. Sobre el nacionalismo de los años '30, v. Lvovich (2006: 52-58).

${ }^{17}$ Ríos, J., ob. cit., p. 4.

18 “Tacuara y el Movimiento Nacional” (s/f), Tacuara. Órgano del Movimiento Nacionalista Revolucionario Tacuara n.3, noviembre, 1963, p. 3.
} 
Campos. La prensa del Movimiento Nacionalista Revolucionario Tacuara en las mutaciones del nacionalismo...

y traidores, que pretenden frustrar al Movimiento, tratándolo de encuadrarlo en el régimen, convirtiéndolo en un partido burgués más... ${ }^{19}$

La solución era promover a los cuadros juveniles en la dirección del peronismo, ya que estos tendrían la capacidad para elevar su nivel de conciencia y organizar la acción revolucionaria. Así se articularía la "trilogía necesaria para la Liberación Nacional: fuerzas sociales aptas, con una doctrina revolucionaria, encuadrados en un Movimiento operante". El MNRT se sentía parte del peronismo por compartir la doctrina nacionalista revolucionaria y los objetivos de liberación nacional, pero intentaba preservar su identidad como grupo separado, ya que creía necesario defender su "individualidad en cuanto a organización, jerarquías y métodos de acción". Si el proletariado era la única clase explotada con conciencia nacional, el movimiento peronista era el terreno a roturar para iniciar el proceso revolucionario. Pero antes, era preciso ajustar cuentas con las concepciones racialistas de la Tacuara nacionalista.

\section{Raza, clase y tercermundismo}

¿Ve?... Nadie puede decir que Fidel Castro sea antisemita. Pero es un nacionalista cubano, terminó con los explotadores, y la mayoría de los judíos se tuvo que ir. (Joe Baxter, en Primera Plana n. 55 26/09/63).

En paralelo a la crisis y descomposición del MNT, en varios puntos del país se inició una ola de atentados antisemitas que alcanzó su clímax entre 1960 y 1962 , coincidiendo con el secuestro del criminal de guerra nazi Adolf Eichmann por parte de un comando israelí. El primer caso de fuerte repercusión en la opinión pública ocurrió en 1962, cuando la estudiante Graciela Sirota acusó a grupos antisemitas de haberla raptado, torturado y dibujado una cruz esvástica en su pecho con una navaja. El segundo fue el atentado contra Raúl Alterman en 1964, asesinado a balazos por miembros de Tacuara en represalia por la muerte de tres miembros de la organización en un enfrentamiento con militantes del Partido Comunista. En conferencia de prensa, los padres de la víctima mostraron una carta recibida tras el crimen, que decía: "Nadie mata porque sí nomás; a su hijo lo han matado porque era un sucio judío" (Gutman, 2003, pp. 229). Fue entonces entre fines de la década de 1950 y comienzos de los años '60 que Tacuara labró su fama en los medios de comunicación como un grupo de choque antisemita.

Todo cambió con la separación del MNRT a fines de 1962. Varios meses después de romper con la dirección de Ezcurra Uriburu, Baxter declaró al semanario Primera Plana: "Hacer antisemitismo ahora es crear un problema artificial de tipo diversionista. Divide inútilmente y crea confusión en torno del verdadero enemigo". ${ }^{20}$ Ahora bien,

19 “Tacuara y el Movimiento Nacional” (s/f), Tacuara. Órgano del Movimiento Nacionalista Revolucionario Tacuara n.3, noviembre, 1963, p. 3.

20 "Variante: una Tacuara izquierdista", Primera Plana, n. 55, 26/09/63. Poco antes de la ruptura con el MNT, Baxter afirmaba en el periódico Mundo Israelita: "Hemos encontrado antisemitas en todos los 
¿esa definición era compartida por el conjunto del MNRT? ¿Se pueden encontrar rastros del primigenio racialismo de la Tacuara nacionalista en la prensa de la Tacuara revolucionaria? Como parte de una organización joven que estaba dando sus primeros pasos, la editorial del primer número de Tacuara del manchón empieza por diferenciar el "viejo nacionalismo" nacido en los años '30, del nuevo nacionalismo que representaría el MNRT. Aquel nacionalismo originario había fracasado por su carácter europeo, ya que replicaba las ideologías nazi-fascistas en alza durante el período de entreguerras, aptas para nacionalidades maduras y grandes imperios, pero fuera de lugar en la Argentina, donde no existía una nación plenamente formada. Desde el punto de vista emenerretista, el viejo nacionalismo había negado el status colonial, puesto que "un falso orgullo les impedía ver a nuestro país en pie de igualdad con la India, el Congo o Argelia". ${ }^{21}$ En consecuencia, los argentinos tenían más parentesco con los países del Tercer Mundo antes que con Europa. Esta estrategia de espacialización simbólica producía indudables dividendos, ya que generaba una sensación de cercanía y simultaneidad entre la alicaída situación política argentina, y los procesos revolucionarios de Argelia, China, Cuba y Vietnam (Gil, 2003).

En Tacuara del manchón es imposible encontrar referencias antisemitas, un silencio en sintonía con la autocrítica que había realizado Joe Baxter en entrevistas a medios de prensa, y frente a un público izquierdista en la Facultad de Filosofía y Letras de la UBA. Sin embargo, la cuestión racial apareció entre sus páginas desde el primer número. En la editorial firmada por Baxter se puede ver una definición inicial sobre el tema:

Creemos que la realidad humana de América está constituida por el aporte de tres grandes grupos raciales, blancos, negros e indios, entre los que no existen ningún tipo de barreras. Creemos que la realidad espiritual de América está dada por el catolicismo, pero entendiendo que todas las demás minorías religiosas merecen nuestro respeto, en la medida en que no se conviertan en factor de desunión o en órganos de penetración colonial. $^{22}$

El pasaje revela un discurso ideológico que, a pesar de proclamar la igualdad racial, no toma ninguna distancia de la tradición nacional-católica. Si como sostiene el linguista Teun Van Dijk, las ideologías se adquieren y modifican con lentitud, los argumentos de Tacuara del manchón, más allá de escenificar a una Tacuara libre de antisemitismo, enarbolan una forma de racismo prescindente de la jerarquización biologicista del racialismo "científico". El argumento de tolerar a las minorías

sectores políticos del país: en los radicales, en los comunistas, en los conservadores, en todos los partidos socialistas. No sé qué les dirán a los judíos pero en todos esos sectores hemos estado con gente que tiene una postura frente al judaísmo similar a la nuestra", v. Gutman (2003, p. 127).

${ }^{21}$ Baxter, J. J., "Nacionalismo", Tacuara. Órgano del Movimiento Revolucionario Tacuara, n.1, octubre, primera quincena, 1963, p. 1.

${ }^{22}$ Baxter, J. J., "Nacionalismo", Tacuara. Órgano del Movimiento Revolucionario Tacuara, n.1, octubre, primera quincena, 1963 , p. 1. 
religiosas siempre y cuando no actuaran como agentes disolventes de la nacionalidad, era una prolongación de las propuestas de homogeneización cultural del MNT, que procuraban asimilar o bien marginar a la colectividad judía. La plataforma de la Unión Cívica Nacionalista, que había permitido al MNT presentarse a elecciones en 1962, prohibía la inmigración de "culturas no asimilables", mientras que el Programa Básico Revolucionario de Tacuara vedaba el ejercicio de la enseñanza y el proselitismo a las religiones no católicas (Gutman, 2003, pp. 120-295). En público, la Tacuara nacionalista negaba las acusaciones de racismo: su judeofobia no tenía causas raciales, sino políticas y religiosas, una estrategia de encubrimiento a tono con las mutaciones del racismo culturalista (Wieviorka, 1994, p. 39). Por otra parte, en algunas notas de Barricada se pueden encontrar marcas de antisemitismo explícito, como invectivas al "gorilaje judaizante", o el cuestionamiento a la Ley de enfiteusis de Bernardino Rivadavia como una maniobra "típicamente judaica". ${ }^{23}$ ¿Esto quiere decir que la ideología emenerretista era una simple continuación del antisemitismo por otros medios? Lejos de esa posibilidad, la mutación de Tacuara del manchon, si bien tenía presentes algunos elementos nacional-católicos del discurso tacuarista tradicional, significó en buena medida un pasaje de la guerra de religión a la lucha de clases.

En el artículo "Vigencia del Tercer Mundo", Joe Baxter desarrolló las ideas que había anunciado en el primer número de Tacuara del manchón. Desde su punto de vista, el Tercer Mundo era una realidad política, económica y social, una geografía de la revolución que no estaba determinada por la pertenencia racial, sino por el antagonismo entre explotadores y explotados:

En primer lugar, debemos aclarar que en ningún momento se hizo mención de un factor biológico, racial, dérmico, piloso, etc., por lo tanto son sumamente ridículas todas las manifestaciones que hacen aparecer al tercer mundo como una elucubración de chiquilines influenciados por algún 'ideólogo' de la izquierda nacional, que llevados por una cierta mentalidad [ilegible] hacen una apología de la negritud. En cuanto al problema de la elección entre los blancos y los negros, es muy simple la definición. Entre un bello ejemplar de capitalista y explotador, de cabellos rubios y lacios, de piel blanca y ojos azules y un explotado baluba, [ilegible], crespo y negro, nos quedamos con el negro, por el lado inverso si la elección se hace entre un señor Tshombe, negro, pero capitalista, explotador, verdugo de su propio pueblo y director importante de trusts internacionales y un trabajador blanco explotado por esos mismos trusts, nosotros nos quedamos con el blanco; o sea que el problema no se da entre blancos y negros sino entre explotadores y explotados, si los explotadores blancos son

\footnotetext{
23 “Los gorilas se desnudan”(s/f), Barricada, n. 2, noviembre, 1963, p. 4; L.G., "Nuestra Revolución”, Barricada
} n. 2, noviembre, 1963, p. 3; Laura, M., "Romper el sistema", Barricada, n.4, diciembre, 1963, p. 1. 
muchos más que los explotadores negros, no es ello motivo de orgullo para la raza blanca. ${ }^{24}$

Esta parte es quizás la que mejor expresa el discurso de transición que asumió el sector Baxter-Nell del MNRT. Aún cuando el artículo dejaba de lado las definiciones peyorativamente racistas para optar por una grilla que clasificaba las diferencias sociales según criterios de clase, también continuaba racializando una parte de sus enunciados. Si para Baxter "la proporción de raza blanca en la Argentina es abrumadora, lo mismo que su origen europeo", era preciso englobar esta parcialidad en un conjunto mayor:

...nosotros sabemos también que Argentina forma parte de una nación por construir Hispano América, en la cual el aporte de otras razas es de capital importancia, y que para el desarrollo futuro de esa gran nación es imprescindible la colaboración de indios, blancos y negros (colaboración e integración que nadie, salvo algún colonialista extranjero o algún enfermo mental nativo puede poner en duda). Para nosotros la identificación con el tercer mundo no se da a través de los colores de nuestra piel sino por nuestra condición de explotados, al igual que los africanos o los asiáticos, los latinoamericanos tenemos un denominador común que es el subdesarrollo, el hambre y la opresión colonialista. ${ }^{25}$

De nuevo, aquí aparece una tensión sistemática entre categorías étnicas y clasistas. Si bien el factor determinante en última instancia era claramente socioeconómico, se seguía subrayando la cuestión racial, ya sea como un remanente de la cultura política que el MNRT de Baxter y Nell quería desprenderse, ya sea para convencer a las bases del "viejo nacionalismo" que la Argentina había sido reducida a un status colonial similar al de Argelia, el Congo o la India. La especialización y tercermundización de la revolución emenerretista era tal, que en una nota sobre las movilizaciones del 17 de octubre de 1945 se señalaba que: "el nacimiento del Tercer Mundo era refregado sobre las caras de los Gainza Paz, los Codovila y los Braden". ${ }^{26} \mathrm{El}$ joven proletariado de las jornadas que dieron nacimiento al peronismo, en cuyos "rostros y lenguaje se observaba su origen provinciano", sellaba un imaginario vínculo de sangre con los países de Asia, África y América Latina. El periódico Barricada, por el contrario, estableció una nota discordante en relación al tercermundismo de Tacuara del manchón, en su esfuerzo por

\footnotetext{
${ }^{24}$ Baxter, J. J., "Vigencia del Tercer Mundo", Tacuara. Órgano del Movimiento Nacionalista Revolucionario Tacuara n.3, noviembre, 1963, p. 2. Moise Tshombe (1919-1969), fue un hombre de negocios de ideas cristianas, anticomunistas y pro-occidentales, que proclamó la independencia del efímero estado de Katanga, una provincia escindida de la República Democrática del Congo en 1960 con apoyo de Francia y Bélgica.

${ }^{25}$ Baxter, J. J., ob. cit., p. 2

26 "Lealtad al 17" (s/f), Tacuara. Órgano del Movimiento Revolucionario Tacuara, n.2, octubre, segunda quincena, 1963, p. 1.
} 
Campos. La prensa del Movimiento Nacionalista Revolucionario Tacuara en las mutaciones del nacionalismo...

marcar una diferencia entre el nacionalismo del MNT y la izquierdización del grupo comandado por Baxter y Nell:

Últimamente se les ha dado a unos nacionalistas descubrir al
"Tercer Mundo" afroasiático, en el cual ubican a Indoamérica
(felicitaciones, Ramos!) y hasta a la Argentina. Se consideran
solidarios de cualquier caníbal habido o por haber. Basta tener
la tez oscura y el pelo crespo para recibir de ellos conmovedores
manifestaciones de amor y admiración. Nuestro país, europeo
por su sangre, su cultura y su historia, se encuentra así junto con
el Congo y Argelia entre los proveedores naturales de carne de
cañón para las batallas de la guerra fría, tan provechosas para
los dos capitalismos internacionales. ¿Cuál será el complejo de
inferioridad de estos muchachos para que siempre, frente a un
nacionalista blanco y un nacionalista negro se sienten atraídos
por este último?

Esta nota parece dialogar hasta en los más mínimos detalles con el artículo de Baxter sobre la vigencia del Tercer Mundo, si bien ambos textos fueron publicados en octubre de 1963. El sector Ossorio del MNRT, al igual que el grupo liderado por Baxter y Nell, tenía una composición plebeya en relación a la Tacuara originaria, adhería al peronismo duro y se identificaba con el revisionismo histórico. Sin embargo, la apropiación de las ideas comunitaristas de Jaime María de Mahieu le dio una identidad propia, ya que Barricada interpelaba al proletariado de manera sistemática, caracterizaba a la Unión Soviética como un capitalismo de Estado, y empleaba tópicos racialistas en forma peyorativa. Para el sector Baxter-Nell del MNRT, el racismo había quedado fuera de tiempo y lugar frente a la avanzada de las revoluciones anticoloniales del Tercer Mundo. En consecuencia, lo más importante era "el color de millones de manos pidiendo el fusil". ${ }^{28}$

\section{Consideraciones finales}

Tacuara irrumpió en la escena política durante la segunda posguerra, una bisagra del siglo XX marcada por los conflictos, reacomodos y mutaciones político-culturales globales, donde la guerra fría hizo saltar los marcos de referencia simbólica del antiguo nacionalismo. En esta nueva coyuntura, una parte de la Iglesia católica y los nacionalistas coincidió con los demócratas, los liberales y la política exterior norteamericana en la

${ }^{27}$ M., “iCuidado con la izquierda nacional!”, Barricada, n.2, noviembre, 1963, p. 2.

${ }^{28}$ Baxter, J. J., ob. cit., pág. 2. El testimonio de Alfredo Ossorio ofrece una interpretación de las diferencias con el sector Baxter-Nell: "En el 62, junto con la expulsión mía y la declaración de ruptura que efectué, Baxter hace lo propio frente a la izquierda universitaria. Entonces el pésame frente a estos grupos que hizo Joe no me gustó. Pensé que sus interlocutores no tenían tamaño para ser nuestros confesores. Decirles 'nosotros que venimos de la derecha', era obviar que gran parte de los destinatarios del mensaje jugaron con la derecha y para la derecha en ocasiones históricas importantes de la historia argentina", véase: Campos (2016, p. 90). 
cruzada contra el comunismo. La defensa de los valores "occidentales y cristianos" tensionó el imaginario nacionalista, que había alcanzado un notable desarrollo en la Argentina entre 1930 y 1945, en oposición a la democracia liberal y al expansionismo anglosajón. Con la caída del gobierno peronista en 1955, se constituyó un campo político signado por la dispersión, las mezclas y los tránsitos políticos, a mitad de camino entre una época de intensa polarización alrededor de la dicotomía peronismo-antiperonismo (entre 1945 y 1955), y otro momento de polarización aún más violenta, cuyo principal vector sería la dicotomía izquierda-derecha en los años '70. Una primera hipótesis de trabajo para comprender el desplazamiento de sectores del MNT a posiciones lindantes con el peronismo y la izquierda, sería pensar que el nacionalismo de Tacuara fue una respuesta al nuevo escenario global planteado por la guerra fría. Si el catolicismo ultramontano quedó del mismo lado que el imperialismo norteamericano y las fuerzas armadas, varios militantes de derecha atraídos por el nacionalismo de Cuba, Egipto y Argelia concluyeron el duelo con el universo simbólico de la Segunda Guerra Mundial, para converger con sectores del peronismo, el catolicismo y las izquierdas en la constelación tercermundista.

El MNRT se formó en un contexto de suma inestabilidad política en la Argentina, durante el interinato de José María Guido al frente del Poder Ejecutivo. Para los militantes emenerretistas, el sindicalismo peronista era la única fuerza con arraigo popular que existía para realizar una transformación radical de las estructuras sociales, siempre y cuando contara con una dirección combativa y una doctrina revolucionaria. Aunque ambos elementos parecían latir dentro del peronismo, solo la alianza entre el nuevo nacionalismo y las juventudes peronistas podrían revertir las tendencias reformistas y burocráticas en la cúspide del movimiento. Los tacuaristas, como parte del nacionalismo argentino, se encontraban frente a una crisis de referencias políticas: para ellos, las revoluciones nacionales que encarnaban el falangismo español, el fascismo italiano y el nazismo alemán habían sido aplastadas o domesticadas por las potencias aliadas. La oposición al imperialismo anglosajón, el control estatal de la economía y la promoción de gobiernos fuertes con apoyo popular ya no se encontraban en la Europa blanca, si no en un Tercer Mundo cuyos movimientos revolucionarios se identificaban con un nacionalismo izquierdista y socializante.

En el ámbito local, el peronismo fue un dique para las aspiraciones nacionalistas: la expansión del movimiento justicialista, su intervencionismo estatal y la incorporación al discurso oficial de varios tópicos nacional-populares de los años '30 y '40, funcionó como un polo de atracción que dividió a las organizaciones de derecha. Adicionalmente, después de 1955 el peronismo sedujo a los nacionalistas más jóvenes que ingresaron al MNT por la impronta rebelde y plebeya que había adquirido en los primeros años de la resistencia. La recomposición del peronismo tuvo un efecto fragmentador sobre el tacuarismo similar al que había vivido la Alianza Libertadora Nacionalista en la década anterior, ya que las rupturas de la GRN, el MNA y el MNRT tuvieron en mayor o menor medida que ver con el posicionamiento de Tacuara frente a Perón y el sindicalismo peronista (Goebel, 2007, pp. 356-377 y Lvovich, 2009, p. 6). La respuesta 
Campos. La prensa del Movimiento Nacionalista Revolucionario Tacuara en las mutaciones del nacionalismo...

emenerretista a los bruscos cambios de la coyuntura nacional e internacional no fue homogénea. El sector Ossorio, a través de la publicación Barricada, preservó algunos tópicos racialistas del discurso tacuarista y se identificó con las ideas comunitaristas de Jaime María de Mahieu, para demarcar una clara frontera con la izquierda marxista. En Tacuara del manchón, en cambio, se puede observar un esfuerzo de traducción del discurso racialista a categorías socioeconómicas emparentadas con el marxismo, como se advierte en los artículos firmados por Joe Baxter con el reemplazo de las diferencias étnicas por la división entre explotadores y explotados. ${ }^{29}$

¿Puede ser concebido el tránsito de la Tacuara nacionalista a la Tacuara revolucionaria como un proceso de radicalización? Este es un concepto engañosamente transparente, que suele describir un rápido tránsito de las ideas reformistas a las revolucionarias, o bien de los mecanismos de lucha pacífica a los métodos de la violencia política. La historia de los militantes del MNRT difícilmente se ajusta a esta categorización: ¿cuándo y cómo se radicalizaron? ¿Hacia la derecha, cuándo ingresaron al MNT a fines de los años ' 50 ? ¿Hacia la izquierda, cuándo se separaron formalmente de la tutela de Alberto Ezcurra Uriburu en diciembre de 1962? ¿Eran radicales cuando adoptaron los métodos violentos de acción directa, o cuando incorporaron categorías marxistas a su discurso político? ¿El nacional-sindicalismo de Ramiro Ledesma Ramos era menos radical que la recepción de la Revolución argelina o cubana? Si para Marx $(1959$, p. 45) ser radical significaba atacar las cuestiones de raíz, esta premisa que exigía la demolición de las mediaciones, los gradualismos y las etapas se cumplía a rajatabla tanto en el MNT como en el MNRT. Por esta razón, parece más preciso emplear el término de "mutación" identitaria o político-cultural, para caracterizar a activistas que protagonizaron pasajes del nacionalismo de derechas al peronismo de izquierda, de la derecha a la izquierda y viceversa. ${ }^{30}$

En las páginas de Tacuara del manchón se pueden encontrar huellas de una pequeña pero significativa mutación del nacionalismo argentino: el pasaje de la ideología nacional-católica de la Tacuara nacionalista -caracterizada por una teología política en clave racialista- a un nacionalismo más secularizado, interesado en la emancipación económica y social del Tercer Mundo. Este último punto, que ocupa un lugar destacado en los artículos de Joe Baxter, invirtió las premisas antimaterialistas, religiosas y culturalistas que gobernaban la construcción identitaria de la Tacuara nacionalista. Si bien, el Programa Básico Revolucionario del MNT incluyó medidas económicas como la supresión del latifundio, la nacionalización de la banca y el comercio exterior, un examen atento de sus medios de prensa muestra un entramado diferente del discurso tacuarista. ${ }^{31}$ Para las corrientes nacionalistas más tradicionales, detrás del discurso de la

\footnotetext{
${ }^{29}$ La idea de una "traducción” para el diálogo entre cristianos y marxistas en los años “60 es de Sarlo (1993, pp. 71-84)

${ }^{30}$ La crítica al concepto de radicalización fue sugerida al autor por Omar Acha (año de ed.).

${ }^{31}$ Como sostenía el principal referente del MNT: " $1{ }^{\circ}$ Queremos -y por ende creemos- que la verdadera antítesis en nuestro mundo no es democracia o bolchevismo, sino materialismo capitalista e idealismo occidental, basado en las virtudes milenarias de un cristianismo rejuvenecido, militante, exento de pompa estulfiante. $2^{\circ}$ Queremos -y por ende creemos- que la mejor forma de occidentalismo militante consiste
} 
guerra fría que dividía al mundo entre demócratas y comunistas existía un antagonismo primordial, que oponía al occidente cristiano con el materialismo ateo de los Estados Unidos y la URSS. Esta dimensión del discurso tacuarista intervenido por categorías religiosas configura una teología política, en el sentido que Carl Schmitt (2009, p. 37) le daba al sostener que todos los conceptos significativos de la moderna teoría del Estado eran conceptos teológicos secularizados. ${ }^{32}$

Las diferencias entre el discurso del MNT y el MNRT permiten suponer el tránsito de una noción trascendente de la política a otra más inmanente. Si como afirma el filósofo Slavoj Zizek (2005, p. 172) “el truco básico del antisemitismo consiste en desplazar el antagonismo social a un antagonismo entre el tejido social congruente, el cuerpo social, y el judío como la fuerza que lo corroe", el MNRT -sobre todo el sector de Baxter y Nell- hizo el movimiento inverso y representó el antagonismo social en sus textos para desracializar la política, asignándole un lugar central a la lucha de clases y los procesos económicos en general. La mutación de la teología política a la política revolucionaria no se desarrolló de manera "pura", sino que conservó varios elementos de la etapa anterior: la prensa emenerretista siguió recordando a Darwin Passaponti, tal como lo había hecho durante años la Tacuara nacionalista. La reivindicación de Hispanoamérica convivió con las referencias a América Latina y el Tercer Mundo, junto a la continuidad de figuraciones deudoras del revisionismo histórico, como los gauchos, las montoneras y la oligarquía mercantil porteña. Aun así, Tacuara del manchón es una excelente pieza documental que llama la atención por la complejidad de los procesos de mutación político-culturales de los años ‘ 60 .

\section{Referencias bibliográficas}

Bardini, R., (2002). Tacuara. La pólvora y la sangre. México, Océano.

Baschetti, R. (1997). Documentos de la resistencia peronista, 1955-1970. La Plata, De la Campana.

Bozza, J. (2001). “El peronismo revolucionario. Itinerario y vertientes de radicalización”. Sociohistórica $\mathrm{N}^{0}$ 9-10, pp. 135-169.

Bufano, S. y Rot, G. (2006). “Entrevista a Juan Gasparini”. Lucha armada, № 6, pp. 44-55.

en un nacionalismo cerrado, que exalte las virtudes del propio pueblo y arranque sus vicios con mano férrea, v. Ezcurra Uriburu, A., "Nuestra zarza ardiente", Tacuara. Vocero de la Juventud Nacionalista n.7 (1959), pp. 1-2.

${ }^{32}$ El concepto de secularización en Schmitt es ambiguo. Si a primera vista parece reducir lo secular a lo teológico, en realidad se refiere a analogías sistemáticas entre los conceptos teológicos y el pensamiento político moderno, v. Noseto (2014, pp. 11-16). El contenido religioso y culturalista del discurso tacuarista puede verse también en Ezcurra Uriburu, A., "Estilo", Tacuara. Vocero de la Juventud Nacionalista, n. 9, 1960, p. 2. En la misma línea, v Denovi, O. "Más allá del nacionalismo", Ofensiva, s/n., 1963, p. 7; "Textos escogidos de Juan Vázquez de Mella y Fanjul”, Ofensiva, n. 9, agosto, 1962, p. 8; LAB, "Objetivos de la política nacionalista", Ofensiva, n. 11, noviembre, 1962, pp. 5-6; Malm Green, G., "Universidad 'nacional",, Tacuara. Vocero de la juventud nacionalista n. 8, 1960, p. 2; Valenzuela, G. "El gobierno universal”, Tacuara. Vocero de la juventud nacionalista n. 9, 1960, p. 3, "Un viejo enemigo una nueva táctica", en Tacuara. Vocero de la juventud nacionalista, s/n, 1963, p. 2. 
Campos. La prensa del Movimiento Nacionalista Revolucionario Tacuara en las mutaciones del nacionalismo...

Campos, E. (2016). “¿De fascistas a guerrilleros? Una crítica a la historiografía sobre Tacuara". Tiempo Histórico, Año 7, n. 13 (julio-diciembre), pp. 117-134. Universidad Academia de Humanismo Cristiano, Santiago de Chile.

Campos, E. (2016). Entrevista a Alfredo Ossorio. De la derecha nacionalista a la izquierda peronista. En: Pozzi, P. (coord.), Rebeldes e inconformistas. Procesos de politización y rebelión en América Latina. Buenos Aires, Imago Mundi.

Carman, F. (2015). El poder de la palabra escrita. Revistas y periódicos argentinos (1955-1976). Buenos Aires, Biblioteca Nacional.

Dandan, A. y Heguy, S. (2006). Joe Baxter. Del nazismo a la exterma izquierda. La historia secreta de un guerrillero. Buenos Aires, Norma.

Finchelstein, F. (2016). Orígenes ideológicos de la "guerra sucia". Fascismo, populismo $y$ dictadura en la Argentina del siglo XX. Buenos Aires, Sudamericana.

Galván, M. V. (2008). El movimiento Nacionalista Tacuara y sus agrupaciones derivadas. Una aproximación desde la historia cultural. Tesis de Maestría en Sociología de la Cultura, UNSAM-UNGS.

Galván, V.; Padrón, J. M. y Gluck, M. (2012). "Tacuara: entre la revolución nacional y la revolución social”. Entrepasados n. 38-39.

García, K. (1998). "1963: Asalto al Policlínico Bancario. El primer golpe armado de Tacuara", en Todo es Historia, Buenos Aires, № 373, pp. 9-19.

Gasparini, J. (2006). Manuscrito de un desaparecido en la ESMA. El libro de Jorge Caffatti. Del asalto al Policlínico Bancario por Tacuara a las FAP y el secuestro del jefe de la FIAT en París. Buenos Aires, Norma.

Gil, G. (2003). Cristianismo y Revolución: una voz del jacobinismo de izquierda en los 60. Buenos Aires, CEDINCI.

Goebel, M. (2007). "A Movement from Right to Left in Argentine Nationalism? The Alianza Libertadora Nacionalista and Tacuara as Stages of Militancy". Bulletin of Latin American Research 26/3 (United Kingdom), pp. 356-377.

Goldar, E. (1972). La Revolución argelina. Buenos Aires, CEAL.

Gutman, D. (2003). Tacuara. Historia de la primera guerrilla urbana argentina. Buenos Aires, Vergara.

Lvovich, D. (2006). El nacionalismo de derecha, desde sus origenes hasta Tacuara. Buenos Aires, Capital Intelectual.

Lvovich, D. (2009). "La extrema derecha en la Argentina posperonista". Diálogos. Revista del Departamento do História do Programa de Pós-Graduacao em História.13/1 (Maringá), pp. 45-61.

Marx, C. y Engels, F. (1959). Sobre la religión. Buenos Aires, Cartago.

Noseto, L. (comp.). (2014). Lecturas de Carl Schmitt. Forma y contenido de la teología política. Buenos Aires, Instituto de Investigaciones Gino Germani.

Padrón, J. M. (2017). ;Ni yankis ni marxistas!, nacionalistas. Nacionalismo, militancia y violencia política. El caso del Movimiento Nacionalista Tacuara. Buenos Aires, UNSAM-UNGS.

Raimundo, M. (2001). "Compañero y los orígenes del peronismo revolucionario". Sociohistórica, n. 8, pp. 203-226. 
Rock, D. (1993). La Argentina autoritaria: los nacionalistas, su historia y su influencia en la vida pública. Buenos Aires, Ariel.

Sarlo, B. (1993). La batalla de las ideas (1943-1973), Buenos Aires, Emecé.

Senkman, L. (2001). "La derecha nacionalista y los gobiernos civiles". En: Rock, D. (ed.) La derecha argentina: nacionalistas, neoliberales, militares y clericales. Buenos Aires, Vergara. pp. 277-283.

Schmitt, C. (2009). Teología política. Madrid, Trotta.

Tortti, M. C. (2007). El viejo partido socialista y los origenes de la nueva izquierda [En línea]. Tesis doctoral. Universidad Nacional de La Plata. Facultad de Humanidades y Ciencias de la Educación.

Traverso, E. (2014). El final de la modernidad judía. Buenos Aires, FCE.

Van Dijk, T. (2005). "Ideología y análisis del discurso". Utopía y Praxis Latinoamericana, vol. 10, n. 29, Maracaibo, Universidad de Zulia, pp. 9-36.

Wieviorka, M. (1994). “Racismo y exclusión”. Estudios sociológicos, vol. XII, n. 34, pp. 37-48.

Zizek, S. (2005). El sublime objeto de la ideología. Buenos Aires, Siglo XXI.

\section{Referencias documentales}

"Variante: ¿una Tacuara izquierdista?”, Primera Plana, n. 55, 26/09/63.

"Los tacuaristas no somos asesinos, afirma su jefe", Crónica, 04/05/64.

“Generación y juventud”, Tacuara. Vocero Oficial de la UNES n. 4, 1946.

Baxter, J. J., "Nacionalismo", Tacuara. Órgano del Movimiento Revolucionario Tacuara, n.1 octubre, primera quincena, 1963, p. 1.

Ríos, J., "Tacuara y la liberación nacional”, Tacuara. Órgano del Movimiento Revolucionario Tacuara $n .1$ (octubre, primera quincena, 1963, p. 4.

"Lealtad al 17" (s/f), Tacuara. Órgano cvn34w del Movimiento Revolucionario Tacuara, n. 2 octubre, segunda quincena, 1963, p. 1.

Baxter, J. J., "Ben Bella y el Tercer Mundo", Tacuara. Órgano del Movimiento Nacionalista Revolucionario Tacuara, n.2, octubre, segunda quincena, 1963, p. 4.

"Tacuara y el Movimiento Nacional” (s/f), en periódico Tacuara. Órgano del Movimiento Nacionalista Revolucionario Tacuara, n.3, noviembre, 1963, p. 3.

Baxter, J. J., "Vigencia del Tercer Mundo", Tacuara. Órgano del Movimiento Nacionalista Revolucionario Tacuara, n.3, noviembre, 1963, p. 2.

M., “'Cuidado con la izquierda nacional!”, Barricada, n.2, noviembre, 1963, p. 2.

L. G., "Nuestra Revolución”, Barricada, n. 2, noviembre, 1963, p. 3.

"Los gorilas se desnudan" (s/f), Barricada, n. 2, noviembre, 1963, p. 4.

Laura, M., "Romper el sistema", Barricada n.4, diciembre, 1963, p. 1.

Ezcurra Uriburu, A., "Nuestra zarza ardiente", Tacuara. Vocero de la Juventud Nacionalista, n.7 1959, pp. 1-2.

"Servicio de librería Darwin Passaponti", Tacuara. Vocero de la Juventud Nacionalista, n. 71959 , p. 2.

Malm Green, G., "Universidad "nacional", Tacuara. Vocero de la juventud nacionalista, n. 8,1960 , p. 2. 
Valenzuela, G. "El gobierno universal", Tacuara. Vocero de la juventud nacionalista $\mathrm{n}$. 9, 1960, p. 3 .

Ezcurra Uriburu, A., "Estilo", Tacuara. Vocero de la Juventud Nacionalista n. 9, 1960), p. 2. Mille, A., "Occidente, es occidente", Tacuara. Vocero de la juventud nacionalista, n. 10, septiembre, 1961, p. 2.

"Disfrazados", Tacuara. Vocero de la juventud nacionalista s/n., noviembre, 1963, p. 2. "Un viejo enemigo una nueva táctica", Tacuara. Vocero de la juventud nacionalista s/, noviembre, 1963, p. 2.

"Aristocracia revolucionaria" (s/f). Tacuara. Vocero de la juventud nacionalista, año XVIII, s/n, diciembre, 1963, p. 3.

"La democracia no sirve", en periódico Tacuara. Vocero de la Juventud Nacionalista, año XVIII, s/n (diciembre de 1963), p. 4.

Denovi, O., "Más allá del nacionalismo (I). El hecho de la lucha de clases". Boletín Ofensiva, n.9, agosto, 1962, p. 5.

“Textos escogidos de Juan Vázquez de Mella y Fanjul”. Boletín Ofensiva, n. 9, agosto, 1962, p. 8.

Ezcurra Uriburu, A., "La crisis del peronismo". Boletín Ofensiva, n. 11, noviembre, 1962, pp. 3-4.

LAB, "Objetivos de la política nacionalista”. Boletín Ofensiva, n. 11, noviembre, 1962, pp. 5-6.

Denovi, O. "Más allá del nacionalismo". Boletín Ofensiva, s/n., 1963, p. 7. 